\title{
The "Metabolic Winter" Hypothesis: A Cause of the Current Epidemics of Obesity and Cardiometabolic Disease
}

\author{
Raymond J. Cronise, BS, David A. Sinclair, $\mathrm{PhD},{ }^{2,3}$ and Andrew A. Bremer, MD, PhD ${ }^{4, *}$
}

\begin{abstract}
The concept of the "Calorie" originated in the 1800s in an environment with limited food availability, primarily as a means to define economic equivalencies in the energy density of food substrates. Soon thereafter, the energy densities of the major macronutrients - fat, protein, and carbohydrates-were defined. However, within a few decades of its inception, the "Calorie" became a commercial tool for industries to promote specific food products, regardless of health benefit. Modern technology has altered our living conditions and has changed our relationship with food from one of survival to palatability. Advances in agriculture, food manufacturing, and processing have ensured that calorie scarcity is less prevalent than calorie excess in the modern world. Yet, many still approach dietary macronutrients in a reductionist manner and assume that isocalorie foodstuffs are isometabolic. Herein, we discuss a novel way to view the major food macronutrients and human diet in this era of excessive caloric consumption, along with a novel relationship among calorie scarcity, mild cold stress, and sleep that may explain the increasing prevalence of nutritionally related diseases.
\end{abstract}

\section{Introduction}

$\mathrm{I}$ N 400 BC, Hippocrates wrote: "We must consider [whether] food is to be given once or twice a day, in greater or smaller quantities, and at intervals. Something must be conceded to habit, to season, to country and to age." ${ }^{1}$ Twenty-three centuries later, Wilbur O. Atwater, a leading $19^{\text {th }}$ century nutritionist, wrote: "In our practice of eating, we are apt to be influenced too much by taste [and] the dictates of the palate; we are prone to let natural instinct be overruled by acquired appetite. We need to observe our diet and regulate appetite by reason. In doing this we may be greatly aided by the knowledge of what our food contains and how it serves its purpose in nutrition.",2

Today, we are faced with an unprecedented obesity pandemic that is propelling a dramatic rise in chronic agerelated diseases. In fact, individuals who are overweight worldwide now outnumber those undernourished. ${ }^{3}$ Furthermore, information regarding nutrition has never been more voluminous or accessible. Numerous books, blogs, and guidelines provide not only recommendations for how to eat, but also discuss the underlying biology supporting their claims. Traditional scientists and physicians, along with a cadre of citizen scientists, are also earnestly struggling to understand the etiology of the obesity epidemic and its attendant consequences, and how the rise in chronic overnutrition and nutritionally related diseases might be reversed.

\section{The "Calorie"}

In the $1800 \mathrm{~s}$, a fundamental change occurred in the relationship between people and food. Historically, food was simply seen as sustenance. But, in an attempt to understand how food and air functioned to produce work and heat, our current scientific notions of nourishment and nutrition began to develop. Lavoisier overturned the century-old phlogistic doctrine in the late $18^{\text {th }}$ century with his discovery of the role of oxygen in combustion and respiration. Within 50 years, his general ideas of carbon and hydrogen fuel were replaced by Liebig's proposal of specific organic molecules, such as starch or sugars, fats, and albumin, fibrin, and "proteines." 4 These advancements then led to the explanation of the millennium-old curiosities of Aristotle and Galen on the source of "innate heat." ${ }^{5}$ By the close of the

\footnotetext{
${ }^{1}$ Thermogenex, Huntsville, Alabama.

${ }^{2}$ Department of Genetics, Harvard Medical School, Boston, Massachusetts.

${ }^{3}$ Department of Pharmacology, School of Medical Sciences, The University of New South Wales, Sydney, Australia.

${ }^{4}$ Departments of Pediatrics and Medicine, Vanderbilt University, Nashville, Tennessee.

*Current affiliation: National Institute of Diabetes and Digestive and Kidney Diseases, National Institutes of Health, Bethesda, Maryland.
} 
$19^{\text {th }}$ century, a Calorie (technically a kilocalorie or $\sim 4.2$ kilojoules) was defined.

\section{Food}

Scientific advances made during the 1840s marked the beginning of modern nutritional science. Food was now classified as proteins, carbohydrates, or fats based on the majority macronutrient, deemphasizing the fact that whole food typically contains a mixture of constituents. Food went beyond sustenance and now had a designation outside of hunger. In 1875 , having worked with the German nutritional scientists Carl von Voit, Max von Pettenkofer, and Max Rubner, Atwater established a laboratory at Wesleyan University to evaluate systematically the various components of foodstuffs. By 1877 , government funding to promote agriculture by scientific investigation and experiments reached $\$ 5000$ per year. In 1887, 16 of these laboratories existed and the US Congress furthered the work by appropriating $\$ 15,000$ to each state having such a facility; by 1888 , their appropriations grew to $\sim \$ 1,000,000$ annually, with $\sim 25 \%$ coming from nongovernment donations. The promotion of food through food science had become big business. ${ }^{6}$

At these laboratories, the macronutrient ratios of protein, carbohydrates, and fats in over 4000 foods were measured by calorimetry. Atwater popularized the nutritional equivalency of food through the concept of the Calorie, and while retaining the general protein plus fuel paradigm begun by Justus von Liebig, he sought to normalize the nutritive economy of food, while not making any statements per se about health. ${ }^{7}$ Over the next two decades, the US Department of Agriculture stakeholders promoted food products to a starving nation; it was now known that expensive foods were not necessarily more "nutritious" than less expensive foods. For example, beans and rice were equally, if not more nourishing, than more expensive meat. ${ }^{8}$

\section{Protein, Carbohydrates, and Fat}

The business of food was flourishing by the time of Atwater's death and the last published edition of his Principles of Nutrition and Nutritive Value of Food in the early 1900s. ${ }^{9}$ The macronutrient-based marketing of food, particularly protein-based marketing, was exemplified in the following decade by beef versus wheat advertising campaigns, each claiming theirs was the best economic value for protein. ${ }^{10}$ The discovery of vitamins in the 1920s then led to new marketing campaigns aimed at advertising a food's utility based on vitamin content. This approach to food was even adopted in the early $20^{\text {th }}$ century US foreign policy as an economic tool to control food in times of peace and war. ${ }^{10,11}$

However, whole food simply does not fit these labels well. For example, few realize that the common potato, although typically considered a carbohydrate, can be a significant dietary source of protein. ${ }^{12}$ Moreover, the perceived prevalence of protein deficiency and the emphasis that historically had been given to the role of protein in human undernutrition was clarified in Donald S. McLaren's 1974 commentary, "The great protein fiasco." 13 Even kwashiorkor has been shown not to be due to simple protein deficiency, but rather a more complicated gut microbiome-diet relationship. ${ }^{14-16}$

Interestingly, a recent study using a nutritional geometric framework and state-space modeling approach found that folivorous (leaf-eating) mountain gorillas in Uganda prioritize the intake of nonprotein energy (NPE). ${ }^{17}$ Specifically, NPE intake was found to be invariant throughout the year, whereas protein intake was determinant on its availability. The concentrations of protein consumed in relation to total energy when leaves were the major portion of the diet for the gorillas were close to the maximum recommended for humans and similar to high-protein human weight-loss diets. Alternatively, the concentrations of protein in relation to total energy when the gorillas ate fruit-dominated diets were similar to those typically recommended for humans. Gorillas live in a world where Calorie scarcity and abundance change with the season. We have created an environment of ubiquitous, cheap, and tasty Calories and have developed social paradigms that frequently revolve around food.

\section{The Food Triangle}

From the mid- $19^{\text {th }}$ century, food has been conceptualized and promoted as protein plus fuel. And, during times of protein and calorie scarcity, this paradigm makes sense. However, because relatively few societies exist today that suffer from severe protein and calorie deficiencies, a new paradigm may be useful.

Our version of the Food Triangle (Fig. 1) organizes food using an energy density paradigm. It recognizes that essential amino acids (i.e., proteins) are not limiting nutrients in any whole food diet that meets daily energy needs. Rather, plant- or animal-sourced amino acids, in excess of daily requirements, along with carbohydrates and fat, all become fuel. Moreover, since the presence of combined fuels in a meal creates an oxidative priority that affects one's postprandial respiratory quotient (RQ) and resting metabolic rate (RMR), ${ }^{18,19}$ it may be conceptually easier to separate them on the basis of fuel source rather than majority macronutrient composition. This organization of energy density further permits individuals to address their micronutrient requirements (the apex of the triangle) without driving overnutrition (the bottom vertices of the triangle). Not surprisingly, many popular diet schemes fall along one of the descending sides of this food triangle, often eliminating one or more food groups (e.g., "red" meat, fruit, dairy, "white" starches, etc.).

One problem with the macronutrient-based organization of food is that it legitimizes certain foodstuffs as equivalent and nourishing as whole food. It additionally focuses consumers on often confusing goals (i.e., eating low-glycemic, complex carbohydrates) rather than simple messages (i.e., eat carrots). It also neglects Atwater's $19^{\text {th }}$ century warnings of acquired appetite and does not account for the impact diet plays on both the gut microbiome ${ }^{20-23}$ and macronutrients in excess of their requirement, while neglecting calorie-limited and vitamin-, mineral-, and phytonutrient-rich plant foods. ${ }^{24-28}$

\section{Calories and Mitochondrial Dysfunction}

At a cellular level, mitochondrial stress and bioenergetics have been linked to chronic overnutrition affecting overall cellular redox circuits. ${ }^{29-31}$ Excess alcohol, branched-chain amino acids (BCAA), fructose, and trans fats have all been shown to affect mitochondrial function and enhance intrahepatic fat when energy replete, ${ }^{32,33}$ and although numerous studies have demonstrated that de novo lipogenesis 


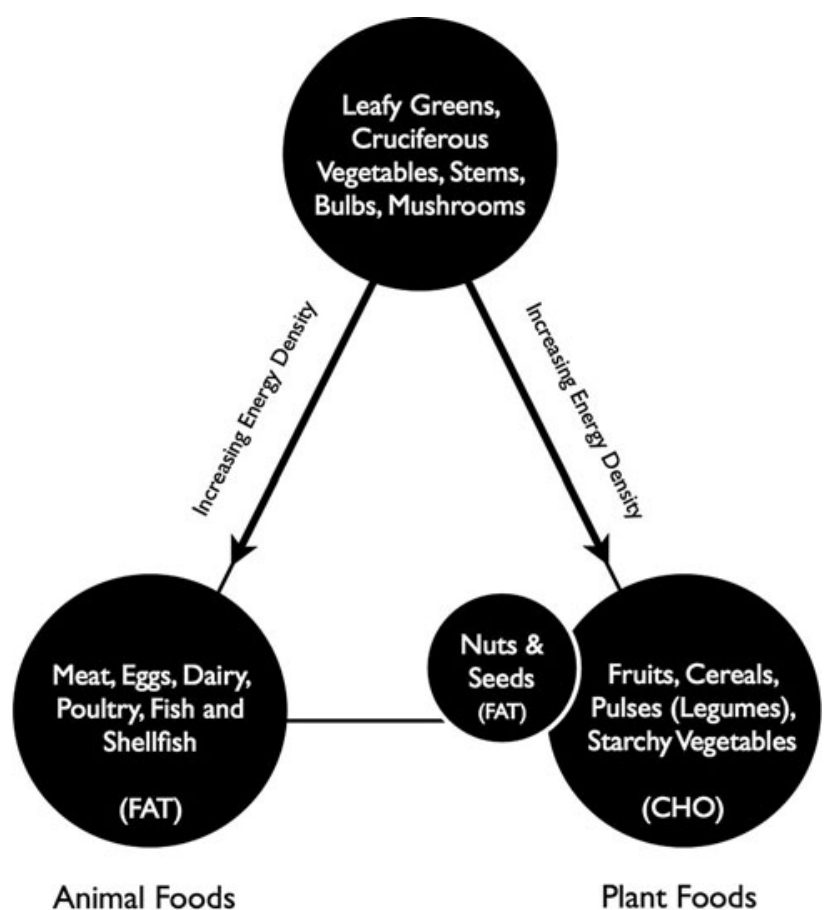

FIG. 1. The Food Triangle. The Food Triangle organizes whole food using an energy density paradigm. It recognizes that essential amino acids (i.e., proteins) are not limiting nutrients in any whole food diet that meets daily energy needs. Rather, vegetable- or animal-sourced amino acids, in excess of daily requirements, along with carbohydrates (CHO) and fat (FAT), all become fuel. This organization of energy density permits individuals to address their micronutrient requirements (the apex of the triangle) without driving chronic overnutrition (the bottom vertices of the triangle). These foods become the nutritional foundation of daily meals, rather than the more energy-dense alternatives. They also provide a rich source of phytonutrients and can be eaten in nearly unlimited quantities. It further places emphasis on foods that are increasingly important for healthy gut microbiota. With the exception of nuts and seeds (plantsourced fats, which can provide the required $\sim 1 \%-3 \%$ of dietary essential fatty acids), foodstuffs and fuel source may be more easily recognized by classified as either "animalbased" foods or "plant-based" foods based on their nonprotein energy source. CHOs may also drive dietary fat storage through shifts in postprandial respiratory quotient (RQ)/resting metabolic rate (RMR). In addition to increased fat storage, it may be more difficult to recognize energy excesses when crossing over from primarily $\mathrm{CHO}$-sourced fuel to fat-sourced fuel or vice versa. Highly refined oils and fats, sugars, and grains are not listed, as they are not whole foods and should be consumed in limited quantities.

does not significantly contribute to obesity per se ${ }^{34-39}$ the general "sugar turns to fat" myth prevails, detracting focus from the negative metabolic effects these substrates have on the liver.

Contrary to overnutrition and calorie excess, calorie restriction typically delays diseases of aging and extends life span. ${ }^{40,41}$ Whether in yeast or mammals, a reduction in calories by $30 \%-40 \%$ from ad libitum feeding triggers a network of genes that evolved to protect organisms during times of food scarcity (i.e., "longevity" genes). Alternatively, excessive intake of macronutrients, for example, the essential amino acid methionine, is negatively correlated with longevity. ${ }^{42,43}$ This "longevity survival network" includes insulin/insulin-like growth factor-1 (IGF-1) signaling, mammalian target of rapamycin (mTOR), AMPactivated protein kinase (AMPK), and the seven sirtuins (SIRT1-7), a family of cellular energetics and defense enzymes. ${ }^{44-46}$ In fact, sirtuin-activating compounds (STACs), such as resveratrol and fisetin, and other calorie restriction mimetics, such as metformin, are thought to derive the majority of their health benefits not from antioxidant properties or by inducing a cellular damage response (hormesis), but rather from interacting with conserved regions in enzymes that have evolved to sense molecules in the environment. ${ }^{47,48}$ The "xenohormesis hypothesis" suggests that STACs act as an advance warning generated by plants in times of stress or deteriorating environmental conditions, and that these stress-signaling molecules may coordinate sirtuin-mediated defenses across species. ${ }^{49-52}$

\section{Metabolic Winter}

Sirtuins function to maintain homeostasis and secure an organism's survival when exposed to internal or external perturbations, and there is an abundant literature demonstrating their role(s) in obesity, metabolic syndrome, diabetes, cancer, inflammation, and cardiovascular disease. ${ }^{53-59}$ SIRT1, in particular, is a key regulator of energy homeostasis and metabolism via peroxisome proliferator-activated receptor-gamma coactivator $1 \alpha(\mathrm{PGC}-1 \alpha)^{60}$ and hypoxiainducible factor $1-\alpha(\mathrm{HIF}-1 \alpha),{ }^{61}$ all of which are critical mediators of mitochondrial biogenesis and possibly responsible for many of the health benefits of dieting and exercise. Interestingly, the other main function of PGC- $1 \alpha$ involves another survival trait, nonshivering thermogenesis, ${ }^{62}$ during which individual mitochondrion bypass adenosine triphosphate (ATP) production and instead create heat by activating uncoupling protein 1 (UCP-1). ${ }^{63}$ This is a very efficient mechanism to replace the immediate response to cold, shivering, with a mechanism that produces heat directly through the recruitment of mitochondria.

Although all skeletal muscle cells are associated with adaptive thermogenesis, ${ }^{64}$ brown adipose tissue (BAT) is also a key player in metabolism. Humans are born with more fat than any other species and have significant amounts of BAT; but, until recently, it was thought to be lost by adulthood. ${ }^{65,66}$ New studies suggest that not only can adults have significant amounts of BAT, ${ }^{67-69}$ but that exercise-induced production of irisin causes an increase in BAT and an associated increase in energy expenditure. ${ }^{70}$ These findings support the notion that modern humans evolved to cope with seasonally cool temperatures (cold stress) and periodic periods of food scarcity (calorie restriction).

\section{Sleep and Body Temperature}

Our current society is one that is chronically sleep deprived. Links between sleep and metabolic dysfunction can be found in early Roman medicine, and too little sleep is associated with obesity and many cardiometabolic diseases. $^{71-74}$ Early observations ranging from Australian aborigines to the cold climate of the Scandinavian nomadic Lapps demonstrate how adaptable humans are to mild cold stress during sleep. ${ }^{75-77}$ Adaptation also occurs for nonnative 
inhabitants after repeated exposure. ${ }^{78}$ Furthermore, until the $20^{\text {th }}$ century, winter was characterized by long nights without artificial light and generally cooler sleeping conditions.

Importantly, much of the same biology that allows winter adaptation for cooler environments, including sleep, overlaps the underlying metabolic mechanisms involved in adaptations to calorie scarcity. ${ }^{79}$ For example, increased sleep in cool environments and long nights of winter in the absence of excess artificial light and warmth may work synergistically to promote the conservation of valuable calories in a time of year when they are naturally scarce. ${ }^{80}$ Melatonin, a hormone associated with sleep, acts to lower the core body temperature, ${ }^{81-84}$ and a steep rate of decline in core body temperature is associated with both sleep onset and quality. ${ }^{85,86}$ In contrast, reduced sleep leads to impaired glucose tolerance and insulin resistance, ${ }^{87}$ increased appetite through changes in leptin and ghrelin levels, ${ }^{88}$ and reduced energy expenditure. ${ }^{89}$ One might conceptually associate winter's cold, dark, and still environment as a natural balance to summer's warm, bright, and active environment. Very few of us now sleep in the cold, and studies have even shown an association between weight gain and average room temperature. ${ }^{90}$

Furthermore, "longevity" genes are central to the regulation of biological circadian rhythms, including those that regulate sleeping, eating, and hormone and neurotransmitter secretion. ${ }^{91,92}$ Importantly, perturbations of the internal clock system and sleep are established risk factors for obesity, diabetes mellitus, and cardiovascular disease and are associated with metabolic dysfunction. ${ }^{93-95}$ Moreover, there appears to be a reciprocal relationship between circadian rhythms and metabolism: Although the circadian clock indeed regulates multiple metabolic pathways (including glucose and cholesterol metabolism), metabolites and feeding behavior can also regulate the circadian clock. ${ }^{96}$ Thus, disruption of genes regulating circadian rhythms, including the "longevity" genes, either alone or in combination with diet-induced changes in systemic metabolites and feeding behavior, may underlie the molecular link between sleep deprivation and altered sleeping patterns such as rotating shift work and cardiometabolic disease.

\section{Putting It All Together}

It appears that we have an evolutionary discordance between our biology that evolved to counter seasonal calorie scarcity and mild cold stress and our modern world of ubiquitous calories and excess warmth. When discussing solutions to the obesity pandemic, the almost universal mantra is "eat less, move more." While no one loses weight by eating more total calories, it has been demonstrated that the average daily energy expenditure of traditional huntergatherers was no different than that of modern day Western (United States and European) counterparts. ${ }^{97}$ This suggests that dramatic differences in lifestyle activity have minimal effects on total energy expenditure and that variances in obesity prevalence among populations result primarily from differences in energy intake rather than expenditure. Moreover, obese people generally have a higher RMR and energy expenditure than the nonobese. ${ }^{98}$ Although it seems reasonable to assume that obesity is a result of less activity, several studies have shown the fallacy of expecting exercise to promote significant weight loss without dietary changes. ${ }^{99,100}$ Thus, it might be reasonable to consider that many of the health benefits of physical activity are actually adaptive responses related to times of cold stress and shivering. In nature, animals do not intentionally participate in high levels of activity to mitigate excess calorie ingestionavailable calories are limited and animals conserve activity. In fact, the main factors influencing energy expenditure are body mass and ambient temperature, not activity. A recent study even demonstrated that energy expenditure from physical activity in humans has not declined since the 1980s and matches energy expenditures of wild mammals. ${ }^{101}$ Thus, since energy expenditure from physical activity has not significantly declined over the same period of time that obesity rates have risen and modern daily energy expenditure in humans is comparable to that of current mammals in the wild, decreased energy expenditure is unlikely to have fueled the obesity epidemic.

These observations do not negate the myriad health benefits of exercise or discourage physical activity, nor do they suggest that significant lifestyle changes (including changes to both energy intake and expenditure) cannot impact overall weight; but, increasing exercise time may not be a major factor in obesity prevention for the general public. Simply increasing activity through exercise in the absence of a significant lifestyle dietary modification is unlikely to have a significant impact. On the other hand, lifestyle modifications involving diet alone can significantly impact both obesity and chronic disease.

Which brings us full circle with respect to food. Hippocrates pondered the need for one or two meals a day, and yet now society tends to eat throughout the entire day. Following a meal, postprandial shifts occur in RMR/RQ for at least $4 \mathrm{hr}$ to accommodate the calories consumed ${ }^{102}$; only then do we then resume using "stored" energy. Moreover, skipping meals does not cause a decrease in metabolism; in fact, an increase in metabolism occurs during the first 4 days of a fast. ${ }^{103}$

The nutrition paradigm of protein plus fuel that began in the mid- $19^{\text {th }}$ century changed the perception of eating food from one of sustenance to one of seeking specific nutrition. It popularized marketing campaigns designed to promote the nutrient content of foodstuffs, ignoring the potential for consuming excess calories. In a world of calorie scarcity, the drive for ubiquitous, cheap, and tasty calories was a noble goal. The problem seems to be that we succeeded in combatting malnutrition and now are faced with the reality of chronic overnutrition, with the best advice to prevent overnutrition-related disease being "eat less, move more." Perhaps the most important meal of the day is not to break fast in the face of obesity, but instead to center our plate on nutrient-dense, calorically poor vegetables and fruits. At the very least, we should heed Atwater's advice and not be "...influenced too much by taste" or "let natural instinct be overruled by acquired appetite."

\section{Conclusions}

In this review, we have discussed a novel way to view the major food macronutrients and how the characterization of the nutritional content of food in the human diet may have unintentionally driven excessive caloric consumption, along with a novel relationship among calorie scarcity, mild cold stress, and sleep that are relevant to obesity, metabolic syndrome, and diabetes. In an effort to keep the essay concise and focused, we intentionally did not address each 
disease entity (i.e., obesity, metabolic syndrome, and diabetes) separately; however, subsequent reviews are forthcoming.

Our 7-million-year evolutionary path was dominated by two seasonal challenges - calorie scarcity and mild cold stress. In the last 0.9 inches of our evolutionary mile, we solved them both. Refrigeration and transportation have fundamentally changed the food to which we have access and the environments in which we live. We also sleep less and are exposed to considerably more artificial light, particularly in the winter months. Obesity and chronic disease are seen most often in people and the animals (pets) they keep warm and overnourished. Similar to the circadian cycle and like most other living organisms, it is reasonable to believe we also respond to the seasons and carry with us the survival genes for winter. Maybe our problem is that winter never comes.

\section{Acknowledgment}

This work received funding support from National Institutes of Health (NIH) grant R01 AG028730 to DAS.

\section{Author Disclosure Statement}

No conflicting financial interests exist.

The contents of this article represent the authors' views and do not constitute an official position of the National Institutes of Health or the United States Government.

\section{References}

1. Adams, Francis, ed. The Genuine Works of Hippocrates, vol. 2. The Sydenham Society; 1849: 703.

2. Atwater WO. Food and Diet. In: Yearbook of Department of Agriculture for 1894. 1894: 386.

3. World Disasters Report 2011, Focus on Hunger and Malnutrition. Geneva: International Federation of Red Cross and Red Crescent Societies; 2011: 16.

4. Liebig J. In: Gregory W, Peterson TB (eds). Animal Chemistry or Organic Chemistry in its Application to Physiology and Pathology. 1847.

5. Mendelsohn E et al. Heat and Life: The Development of the Theory of Animal Heat. Cambridge, MA: Harvard University Press; 1964.

6. Atwater WO. Food and Diet. In: Yearbook of Department of Agriculture for 1894. 1894: 106-116.

7. Atwater WO. Foods: Nutritive Value and Cost, no. 23. US Department of Agriculture; 1894.

8. Atwater WO. What we should eat. The Century Magazine 1888;36:257-264.

9. Atwater WO. Principles of Nutrition and Nutritive Value of Food, no. 142. US Department of Agriculture; 1910.

10. Cullather N. The foreign policy of the calorie. Am Hist Rev. 2007;112:337-364.

11. Blunt K, Swain FL, Powdermaker F. Food Guide for War Service At Home. New York: Charles Scribner's Sons; 1918.

12. Woolfe J, Poats SV. The Potato in the Human Diet. Cambridge, UK: Cambridge University Press; 1987.

13. McLaren D. The great protein fiasco. Lancet 1974;304: 93-96.

14. Smith MI, Yatsunenko T, Manary MJ, et al. Gut microbiomes of Malawian twin pairs discordant for kwashiorkor. Science 2013;339:548-554.

15. Gordon JI, Dewey KG, Mills DA, et al. The human gut microbiota and undernutrition. Sci Transl Med 2012; $137 \mathrm{ps} 112$.
16. Claus SP. Fighting undernutrition: Don't forget the bugs. Cell Host Microbe 2013;13:239-240.

17. Rothman JM, Raubenheimer D, Chapman CA. Nutritional geometry: Gorillas prioritize non-protein energy while consuming surplus protein. Biol Lett 2011;7:847-849.

18. Jebb SA, Prentice AM, Goldberg GR, et al. Changes in macronutrient balance during over-and underfeeding assessed by 12-d continuous whole-body calorimetry. Am J Clin Nutr 1996;64:259-266.

19. Prentice AM. Alcohol and obesity. Int J Obes 1995; 19(Suppl 5):S44-S50.

20. Holmes E, Li JV, Marchesi JR, et al. Gut microbiota composition and activity in relation to host metabolic phenotype and disease risk. Cell Metab 2012;16:559-564.

21. Devkota S, Wang Y, Musch MW, et al. Dietary-fatinduced taurocholic acid promotes pathobiont expansion and colitis in Il10-/- mice. Nature 2012;487:104-108.

22. Brown K, DeCoffe D, Molcan E, et al. Diet-induced dysbiosis of the intestinal microbiota and the effects on immunity and disease. Nutrients 2012;4:1095-1119.

23. David LA, Maurice CF, Carmody RN, et al. Diet rapidly and reproducibly alters the human gut microbiome. Nature 2014;505:559-563.

24. Tilg H. Diet and intestinal immunity. N Engl J Med 2012; 366:181-183.

25. Williams DJ, Edwards D, Hamernig I, et al. Vegetables containing phytochemicals with potential anti-obesity properties: A review. Food Res Int 2013;52:323-333.

26. Courts FL, Williamson G. The occurrence, fate and biological activities of C-glycosyl flavonoids in the human diet. Crit Rev Food Sci Nutr 2013; DOI: 10.1080/ 10408398.2012.694497.

27. Russell WR, Hoyles L, Flint HJ, et al. Colonic bacterial metabolites and human health. Curr Opin Microbiol 2013; 16:246-254.

28. Kalač P. A review of chemical composition and nutritional value of wild-growing and cultivated mushrooms. J Sci Food Agric 2013;93:209-218.

29. Guarente L. Mitochondria-a nexus for aging, calorie restriction, and sirtuins? Cell 2008;132:171-176.

30. Fisher-Wellman KH, Neufer PD. Linking mitochondrial bioenergetics to insulin resistance via redox biology. Trends Endocrinol Metab 2012;23:142-153.

31. Muoio DM, Neufer PD. Lipid-induced mitochondrial stress and insulin action in muscle. Cell Metab 2012;15: 595-605.

32. Bremer AA, Mietus-Snyder M, Lustig RH. Toward a unifying hypothesis of metabolic syndrome. Pediatrics 2012; 129:557-570.

33. Weiss R, Bremer AA, Lustig RH. What is metabolic syndrome, and why are children getting it? Ann NY Acad Sci 2013;1281:123-140.

34. McDevitt RM, Bott SJ, Harding M, et al. De novo lipogenesis during controlled overfeeding with sucrose or glucose in lean and obese women. Am J Clin Nutr 2001; 74:737-746.

35. Hellerstein MK. No common energy currency: De novo lipogenesis as the road less traveled. Am J Clin Nutr 2001; 74:707-708.

36. McDevitt RM, Poppitt SD, Murgatroyd PR, et al. Macronutrient disposal during controlled overfeeding with glucose, fructose, sucrose, or fat in lean and obese women. Am J Clin Nutr 2000;72:369-377.

37. Siler SQ, Neese RA, Hellerstein MK. De novo lipogenesis, lipid kinetics, and whole-body lipid balances in humans 
after acute alcohol consumption. Am J Clin Nutr 1999;70: 928-936.

38. Hellerstein MK, Christiansen M, Kaempfer S, et al. Measurement of de novo hepatic lipogenesis in humans using stable isotopes. J Clin Invest 1991;87:18411852.

39. Hellerstein MK. De novo lipogenesis in humans: Metabolic and regulatory aspects. Eur J Clin Nutr 1999; 53(Suppl 1):S53-S65.

40. Haigis MC, Guarente LP. Mammalian sirtuins_emerging roles in physiology, aging, and calorie restriction. Genes Dev. 2006;20:2913-2921.

41. Koubova J, Guarente L. How does calorie restriction work? Genes Dev 2003;17:313-321.

42. Flatt T. Ageing: Diet and longevity in the balance. Nature 2009;462:989-990.

43. Grandison RC, Piper MD, Partridge L. Amino-acid imbalance explains extension of lifespan by dietary restriction in Drosophila. Nature 2009;462:1061-1064.

44. Hall JA, Dominy JE, Lee Y, et al. The sirtuin family's role in aging and age-associated pathologies. J Clin Invest 2013;123:973-979.

45. Guarente L. Calorie restriction and sirtuins revisited. Genes Dev 2013;27:2072-2085.

46. Someya S, Yu W, Hallows WC, et al. Sirt3 mediates reduction of oxidative damage and prevention of age-related hearing loss under caloric restriction. Cell 2010;143:802812.

47. Baur JA, Pearson KJ, Price NL, et al. Resveratrol improves health and survival of mice on a high-calorie diet. Nature 2006;444:337-342.

48. Sinclair DA. Toward a unified theory of caloric restriction and longevity regulation. Mech Ageing Dev 2005;126: 987-1002.

49. Howitz KT, Sinclair DA. Xenohormesis: Sensing the chemical cues of other species. Cell 2008;133:387-391.

50. Lamming DW, Wood JG, Sinclair DA. MicroReview. Small molecules that regulate lifespan: Evidence for xenohormesis. Mol Microbiol 2004;53:1003-1009.

51. Baur JA, Sinclair DA. What is xenohormesis? Am J Pharmacol Toxicol 2008;3:152.

52. Hooper PL, Hooper PL, Tytell M, et al. Xenohormesis: Health benefits from an eon of plant stress response evolution. Cell Stress Chaperones 2010;15:761-770.

53. Haigis MC, Sinclair DA. Mammalian sirtuins: Biological insights and disease relevance. Annu Rev Pathol 2010;5: 253-295.

54. Hubbard BP, Sinclair DA. Small molecule SIRT1 activators for the treatment of aging and age-related diseases. Trends Pharmacol Sci 2014;35:146-154.

55. Guarente L. Sirtuins as potential targets for metabolic syndrome. Nature 2006;444:868-874.

56. Michan S, Sinclair D. Sirtuins in mammals: Insights into their biological function. Biochem J 2007;404:1-13.

57. Firestein R, Blander G, Michan S, et al. The SIRT1 deacetylase suppresses intestinal tumorigenesis and colon cancer growth. PLoS One 2008;3:e2020.

58. Milne JC, Lambert PD, Schenk S, et al. Small molecule activators of SIRT1 as therapeutics for the treatment of type 2 diabetes. Nature 2007;450:712-716.

59. North BJ, Sinclair DA. The intersection between aging and cardiovascular disease. Circ Res 2012;110:1097-1108.

60. Imai S, Yoshino J. The importance of NAMPT/NAD/ SIRT1 in the systemic regulation of metabolism and ageing. Diabetes Obes Metab 2013;15(Suppl 3):26-33.
61. Gomes AP, Price NL, Ling AJ, et al. Declining $\mathrm{NAD}^{+}$induces a pseudohypoxic state disrupting nuclearmitochondrial communication during aging. Cell 2013; 155:1624-1638.

62. Rodgers JT, Lerin C, Gerhart-Hines Z, et al. Metabolic adaptations through the PGC- $1 \alpha$ and SIRT1 pathways. FEBS Lett 2008;582:46-53.

63. Lowell BB, Spiegelman BM. Towards a molecular understanding of adaptive thermogenesis. Nature 2000;404: 652-660.

64. Wijers SLJ, Schrauwen P, Saris WHM, et al. Human skeletal muscle mitochondrial uncoupling is associated with cold induced adaptive thermogenesis. PLoS One 2008;3:e1777.

65. Kuzawa CW. 30 Beyond Feast-famine: Brain evolution, human life history, and the metabolic syndrome. In: Muehlenbein MP (ed). Human Evolutionary Biology. Cambridge, UK: Cambridge University Press, 2010: 518-527.

66. Lean MEJ. Brown adipose tissue in humans. Proc Nutr Soc 1989;48:243-257.

67. Cypess AM, Lehman S, Williams G, et al. Identification and importance of brown adipose tissue in adult humans. N Engl J Med 2009;360:1509-1517.

68. van Marken Lichtenbelt WD, Vanhommerig JW, Smulders NM, et al. Cold-activated brown adipose tissue in healthy men. N Engl J Med 2009;360:1500-1508.

69. Virtanen KA, Lidell ME, Orava J, et al. Functional brown adipose tissue in healthy adults. $N$ Engl J Med 2009;360: $1518-1525$.

70. Boström P, Wu J, Jedrychowski MP, et al. A PGC1- $\alpha-$ dependent myokine that drives brown-fat-like development of white fat and thermogenesis. Nature 2012;481: 463-468.

71. Cappuccio FP, Cooper D, D'Elia L, et al. Sleep duration predicts cardiovascular outcomes: A systematic review and meta-analysis of prospective studies. Eur Heart $J$ 2011;32:1484-1492.

72. Cappuccio FP, D'Elia L, Strazzullo P, et al. Sleep duration and all-cause mortality: A systematic review and metaanalysis of prospective studies. Sleep 2010;33:585-592.

73. Cappuccio FP, D'Elia L, Strazzullo P, et al. Quantity and quality of sleep and incidence of type 2 diabetes: A systematic review and meta-analysis. Diabetes Care 2010;33: 414-420.

74. Cappuccio FP, Taggart FM, Kandala N-B, et al. Metaanalysis of short sleep duration and obesity in children and adults. Sleep 2008;31:619-626.

75. Scholander $\mathrm{P}$, Hammel $\mathrm{H}$, Hart J, et al. Cold adaptation in Australian aborigines. J Appl Physiol 1958;13:211-218.

76. Andersen KL, Nelms J, Wilson O, et al. Metabolic and thermal response to a moderate cold exposure in nomadic Lapps. J Appl Physiol 1960;15:649-653.

77. Hammel H, Elsner R, Le Messurier D, et al. Thermal and metabolic responses of the Australian aborigine exposed to moderate cold in summer. J Appl Physiol 1959;14:605-615.

78. Scholander P, Hammel H, Andersen KL. Metabolic acclimation to cold in man. J Appl Physiol 1958;12:1-8.

79. Bartness TJ, Demas GE, Song CK. Seasonal changes in adiposity: The roles of the photoperiod, melatonin and other hormones, and sympathetic nervous system. Exp Biol Med 2002;227:363-376.

80. Jung CM, Melanson EL, Frydendall EJ, et al. Energy expenditure during sleep, sleep deprivation and sleep following sleep deprivation in adult humans. J Physiol 2011;589:235-244. 
81. Cagnacci A, Kräuchi K, Wirz-Justice A, et al. Homeostatic versus circadian effects of melatonin on core body temperature in humans. J Biol Rhythms 1997;12:509-517.

82. Tan DX, Manchester LC, Fuentes-Broto L, et al. Significance and application of melatonin in the regulation of brown adipose tissue metabolism: Relation to human obesity. Obes Rev 2011;12:167-188.

83. Gilbert SS, Van Den Heuvel CJ, et al. Peripheral heat loss: A predictor of the hypothermic response to melatonin administration in young and older women. Physiol Behav 1999;66:365-370.

84. Kräuchi K, Cajochen C, Wirz-Justice A. A relationship between heat loss and sleepiness: Effects of postural change and melatonin administration. J Appl Physiol 1997; 83:134-139.

85. Campbell SS, Broughton RJ. Rapid decline in body temperature before sleep: Fluffing the physiological pillow? Chronobiol Int 1994;11:126-131.

86. Murphy PJ, Campbell SS. Nighttime drop in body temperature: A physiological trigger for sleep onset? Sleep 1997;20:505-511.

87. Spiegel K, Tasali E, Leproult R, et al. Effects of poor and short sleep on glucose metabolism and obesity risk. Nat Rev Endocrinol 2009;5:253-261.

88. Spiegel K, Tasali E, Penev P, et al. Brief communication: Sleep curtailment in healthy young men is associated with decreased leptin levels, elevated ghrelin levels, and increased hunger and appetite. Ann Intern Med 2004;141:846-850.

89. Benedict C, Hallschmid M, Lassen A, et al. Acute sleep deprivation reduces energy expenditure in healthy men. Am J Clin Nutr 2011;93:1229-1236.

90. Johnson F, Mavrogianni A, Ucci M, et al. Could increased time spent in a thermal comfort zone contribute to population increases in obesity? Obes Rev 2011;12:543-551.

91. Dibner C, Schibler U, Albrecht U. The mammalian circadian timing system: Organization and coordination of central and peripheral clocks. Annu Rev Physiol 2010;72: 517-549.

92. Sahar S, Sassone-Corsi P. Regulation of metabolism: The circadian clock dictates the time. Trends Endocrinol Metab 2012;23:1-8.

93. Eckel-Mahan KL, Patel VR, de Mateo S, et al. Reprogramming of the circadian clock by nutritional challenge. Cell 2013;155:1464-1478.
94. Maury E, Ramsey KM, Bass J. Circadian rhythms and metabolic syndrome from experimental genetics to human disease. Circ Res 2010;106:447-462.

95. Chang H-C, Guarente L. SIRT1 mediates central circadian control in the SCN by a mechanism that decays with aging. Cell 2013;153:1448-1460.

96. Damiola F, Le Minh N, Preitner N, et al. Restricted feeding uncouples circadian oscillators in peripheral tissues from the central pacemaker in the suprachiasmatic nucleus. Genes Dev 2000;14:2950-2961.

97. Pontzer H, Raichlen DA, Wood BM, et al. Hunter-gatherer energetics and human obesity. PLoS One 2012;7: e40503.

98. Prentice AM, Black AE, Coward WA, et al. High levels of energy expenditure in obese women. Br Med J (Clin Res Ed) $1986 ; 292: 983$

99. Shaw K, Gennat H, O'Rourke P, et al. Exercise for overweight or obesity. Cochrane Database Syst Rev 2006;4: CD003817.

100. Hall KD, Sacks G, Chandramohan D, et al. Quantification of the effect of energy imbalance on bodyweight. The Lancet 2011;378:826-837.

101. Westerterp KR, Speakman JR. Physical activity energy expenditure has not declined since the 1980s and matches energy expenditures of wild mammals. Int J Obes 2008; 32:1256-1263.

102. Jebb SA, Prentice AM, Goldberg GR, et al. Changes in macronutrient balance during over-and underfeeding assessed by 12-d continuous whole-body calorimetry. Am J Clin Nutr 1996;64:259-266.

103. Zauner C, Schneeweiss B, Kranz A, et al. Resting energy expenditure in short-term starvation is increased as a result of an increase in serum norepinephrine. Am J Clin Nutr 2000;71:1511-1515.

Address correspondence to: Andrew A. Bremer, MD, PhD National Institute of Diabetes and Digestive and Kidney Diseases 6707 Democracy Boulevard Building 2DEM, Room 6107 Bethesda, MD 20892-5460

E-mail: andrew.bremer@nih.gov 